Full Length Article

\title{
Optimization and kinetic study of biodiesel production through esterification of oleic acid applying ionic liquids as catalysts
}

\author{
Fernanda F. Roman ${ }^{\mathrm{a}, \mathrm{c}}$, António E. Ribeiro ${ }^{\mathrm{c}}$, Ana Queiroz ${ }^{\mathrm{c}}$, Giane G. Lenzi ${ }^{\mathrm{a}}$, Eduardo S. Chaves ${ }^{\mathrm{b}}$, \\ Paulo Brito ${ }^{\mathrm{c}, *}$ \\ ${ }^{a}$ Departamento de Engenharia Química, Universidade Tecnológica Federal do Paraná, Ponta Grossa, Paraná 84016-210, Brazil \\ ${ }^{\mathrm{b}}$ Departamento de Química, Universidade Federal de Santa Catarina, Florianópolis, Santa Catarina 88040-900, Brazil \\ ${ }^{\mathrm{c}}$ Centro de Investigação de Montanha (CIMO), Instituto Politécnico de Bragança, Campus de Santa Apolónia, 5300-253 Bragança, Portugal
}

\section{A R T I C L E I N F O}

\section{Keywords:}

Esterification

Ionic liquids

Biodiesel production

Response surface methodology

Kinetics study

\begin{abstract}
A B S T R A C T
In this study, 1-methylimidazolium hydrogen sulfate, [HMIM] $\mathrm{HSO}_{4}$, ionic liquid, was successfully applied as a catalyst in the biodiesel production through the esterification reaction of oleic acid with methanol. A response surface methodology (RSM) known as Box-Behnken Design (BBD) was applied to optimize the main experimental reaction conditions, using a set of 27 experiments. This optimization was based on the maximization of both the conversion of oleic acid and the Fatty Acid Methyl Esters (FAME) content of the obtained biodiesel samples. It was concluded that the two most relevant parameters for both the conversion and the FAME content were the molar ratio between oleic acid and methanol and the catalyst dosage. Accordingly to the model, the optimum condition for the maximum conversion was determined as being $8 \mathrm{~h}, 110 \pm 2{ }^{\circ} \mathrm{C}, 15: 1 \mathrm{M}$ ratio methanol/oleic acid and a catalyst dosage of $15 \mathrm{wt} \%$, resulting in a 95\% conversion and for the maximum FAME content were $8 \mathrm{~h}, 110 \pm 2{ }^{\circ} \mathrm{C}, 14: 1 \mathrm{M}$ ratio and a catalyst dosage of $14 \mathrm{wt} \%$, leading to a FAME content of $90 \%$. The kinetics of the esterification reaction was also evaluated, and the experimental results were well described using a third-order reaction model. The kinetic parameters were experimentally determined, and the value of the activation energy was $6.8 \mathrm{~kJ} / \mathrm{mol}$ and the pre-exponential factor was $0.0765 \mathrm{~L}^{2} \cdot \mathrm{mol}^{-2} \cdot \mathrm{min}^{-1}$ confirming that the ionic liquid, [HMIM] $\mathrm{HSO}_{4}$, is a good alternative for replacing traditional catalysts for biodiesel production through esterification reaction.
\end{abstract}

\section{Introduction}

Biodiesel is a liquid fuel suitable to replace diesel originated from petroleum. It can be obtained from several renewable sources, such as vegetable oils [1,2], waste cooking oil (WCO) [3-5], algae [6,7], and animal fat [8]. Traditionally, biodiesel, also known as fatty acid methyl esters (FAMEs), is obtained by the transesterification reaction of triglycerides, mainly found in edible vegetable oils $[9,10]$. Edible oils are a feedstock that leads to an expensive final product and it is associated to competition with the food market [11-13]. Alternatively, biodiesel can also be obtained through the esterification reaction of free fatty acids (FFAs), mainly found in oils with lower quality, such as waste cooking oil [10]. The use of WCOs as raw material for biodiesel production has two main advantages: the cost reduction related to the feedstock and, on the other side, it represents an attractive solution to deal with the environmental problems associated with the waste of these oils [11,14].
While the transesterification reaction can be conducted by alkaline or acid catalysis, the esterification reaction can only be promoted using acid catalysts, since the alkaline catalysts give rise to the saponification reaction of the FFAs $[9,10]$. The classical inorganic acid catalysts, such as sulfuric acid, have the disadvantage of leading to long reaction time $[10,14]$, and the use of strong acids can induce equipment corrosion [12]. In this way, research has now been pointed to find alternative catalysts that promote both the transesterification and esterification reactions, in such a way that WCOs can be successfully applied in the biodiesel production. In this context, ionic liquids emerge as substitutes to the traditional catalysts, being widely studied for this purpose $[3,12,15,16]$. The cost of commercially available ionic liquids is, in general, quite high when compared to the usual inorganic catalysts [17]. However, they are preferable due to some important advantages [18-20]. The main advantages of ionic liquids as catalysts relate to their high catalytic performance. Other important advantages are related to the fact that they can be recycled and then reused, and are also

\footnotetext{
* Corresponding author at: Polytechnic Institute of Bragança, Campus de Santa Apolónia, 5300-253 Bragança, Portugal.

E-mail address: paulo@ipb.pt (P. Brito).
} 
quite easy and safe to handle $[12,18]$.

Ding et al. [21] investigated the transesterification reaction of palm oil under microwave irradiation using the ionic liquid $\left[\mathrm{HSO}_{3}-\mathrm{BMIM}\right]$ $\mathrm{HSO}_{4}$. The optimal condition (microwave power $168 \mathrm{~W}$, reaction time $6.43 \mathrm{~h}$, molar ratio methanol/oil $11: 1$ and catalyst dosage $9.17 \mathrm{wt} \%$, reaching a biodiesel yield of $98.93 \%$ ) was determined by a RSM. A high yield of more than $87 \%$ was maintained after six recovery cycles. They also studied the kinetics of the reaction, obtaining an activation energy of $56.12 \mathrm{~kJ} / \mathrm{mol}$. Ullah et al. [22] investigated biodiesel production in a two-step process: an initial esterification of the FFAs of the WCO with ionic liquids and a subsequent transesterification reaction with potassium hydroxide. Optimization was performed for the esterification step. The most promising ionic liquid was the $[B M I M] \mathrm{HSO}_{4}$ and the highest biodiesel yield was obtained with $5 \mathrm{wt} \%$ catalyst dosage, methanol/oil ratio $15: 1,60 \mathrm{~min}$ reaction time at $160{ }^{\circ} \mathrm{C}$ and agitation speed of $600 \mathrm{rpm}$.

In this paper, we first present a selection of a suitable ionic liquid, from a set of five, for the esterification of oleic acid, used as a model compound for a raw-material containing high FFA. Then, we present a complete study for the esterification reaction of oleic acid with methanol, using the selected ionic liquid 1-methylimidazolium hydrogen sulfate, [HMIM] $\mathrm{HSO}_{4}$, as catalyst. Fig. 1 displays the esterification reaction of oleic acid with methanol.

There are a few papers that study the mentioned catalyst for biodiesel production. Xu et al. [23] studied the transesterification reaction of castor oil using the ionic liquid [HMIM] $\mathrm{HSO}_{4}$. They performed optimization by RSM and estimated the optimal conditions as $4 \mathrm{~h}$ reaction time, mole ratio $6: 1$, reaction temperature $77^{\circ} \mathrm{C}$ and catalyst dosage of $12 \mathrm{wt} \%$, leading to a methyl ricinoleate content of $89.82 \%$. The high catalytic activity was maintained for 4 cycles. Sun et al. [24] investigated the esterification reaction of oleic acid using the mentioned catalyst. The optimal condition obtained was a molar ratio of $4: 1$, catalyst dosage of $3.5 \mathrm{~mL}$ and $6 \mathrm{~h}$ reaction time, leading to a $92.5 \%$ conversion. After 9 recovery cycles, the conversion was still above $85 \%$.

In this work, we will present a deep study of the influence of several reaction parameters on both the conversion and the FAME content of the obtained biodiesel samples using a response surface methodology. Currently, there are no published studies related to the prevision of the kinetic parameters for the reaction using the mentioned ionic liquid. Furthermore, this work will present novel experimental and modeling results for the prevision of the kinetic parameters, including the reaction order, reaction rate constant at different temperatures and the activation energy of the esterification reaction of oleic acid using $[\mathrm{HMIM}] \mathrm{HSO}_{4}$ ionic liquid as catalyst.

\section{Materials and methods}

\subsection{Reagents and materials}

All the reagents used for biodiesel production and for quality control analysis were at least of analytical grade and were used without further purification. Oleic acid, tech $90 \%$, was obtained from ThermoFisher (Germany). The ionic liquids, 1-butyl-3-methylimidazolium hydrogen sulfate, 1-butyl-3-methylimidazolium methyl sulfate, 1-methylimidazolium hydrogen sulfate, 1-butyl-3-methylimidazolium methanesulfonate, tributylmethylammonium methyl sulfate, the 37-component FAME mixture Supelco 47885-U and the heptadecanoic acid methyl ester, used as internal standard, were all obtained from Sigma Aldrich (Switzerland). Methanol, n-heptane, absolute ethanol and diethyl ether solvents were obtained from Carlo Erba (France). Concentrated sulfuric acid was obtained from Pronalab (Portugal).

\subsection{General procedure for the esterification reaction}

Ionic liquid, oleic acid and methanol were added to a $1000 \mathrm{~mL}$ reaction vessel. The vessel was immersed in a bath previously heated to a determined temperature, under agitation and methanol reflux. At the end of the reaction, the vessel was removed from the bath and left to cool down to room temperature. The product was centrifuged $(20 \mathrm{~min}$, $3000 \mathrm{rpm}$ ) and stored until the phases were split. After separation of the aqueous and organic phases, the biodiesel phase was heated to evaporate both residual water and methanol in a drying oven and both phases were stored at $4 \pm 2{ }^{\circ} \mathrm{C}$ for further analysis. The same reaction procedure was used for the kinetics experiments, with an additional step of collecting $1 \mathrm{~mL}$ of sample, at pre-specified times. The acidity determination of these samples was immediately done according to the procedure described in the following section.

\subsection{Acidity determination of the biodiesel samples}

Acidity was measured by titration with an alcoholic potassium hydroxide solution, accordingly to EN 14104 standard [25]. The acid value was determined by Eq. (1).

Acidvalue $(\mathrm{AV})\left(\frac{\mathrm{mgKOH}}{\text { gbiodiesel }}\right)=\frac{V_{\mathrm{KOH}} * C_{\mathrm{KOH}} * M W_{\mathrm{KOH}}}{m_{\text {biodiesel }}}$

where $V_{K O H}$ is the volume of the titrant (mL), $C_{K O H}$ is the concentration of the titrant (mol/L), $M W_{K O H}$ is the molar weight of the titrant $(\mathrm{g} / \mathrm{mol})$ and $m_{\text {biodiesel }}$ is the mass of biodiesel ( $\mathrm{g}$ ). The conversion was calculated by comparing the acid value of the initial oleic acid to the acid value of biodiesel samples, using Eq. (2).

$X(\%)=\frac{A V_{\text {oleicacid }}-A V_{\text {biodiesel }}}{A V_{\text {oleicacid }}} \times 100$

where $A V_{\text {oleic acid, }}$ is the acid value of the oleic acid and $A V_{\text {biodiesel }}$ is the acid value of the biodiesel sample, both in $\mathrm{mg} \mathrm{KOH} / \mathrm{g}$ of sample.

\subsection{Determination of fatty acid methyl ester (FAME) content of the biodiesel samples}

Gas chromatography analysis was performed to determine the Fatty Acid Methyl Ester (FAME) content in the obtained biodiesel samples, according to EN 14103 standard [26]. Gas chromatography equipment, GC VARIAN CP-3800, coupled with a flame ionization detector (FID) and equipped with a Supelcowax10 column $(30 \mathrm{~m} \times 0.25 \mathrm{~mm} \times 0.25 \mu \mathrm{m})$ was used for FAME determination. The operational conditions used in the GC were: helium flow of $1 \mathrm{~mL} / \mathrm{min}$, initial oven temperature of $50^{\circ} \mathrm{C}$ (hold for $1 \mathrm{~min}$ ), with a first ramp to $200^{\circ} \mathrm{C}$ at $25^{\circ} \mathrm{C} / \mathrm{min}$ and a second ramp to $230^{\circ} \mathrm{C}$ at $3^{\circ} \mathrm{C} / \mathrm{min}$ (hold for $23 \mathrm{~min}$ ), with a total running time of $40 \mathrm{~min}$. The injector temperature was set at $250{ }^{\circ} \mathrm{C}$, a split ratio of $1: 25$ and a detector temperature set at $250^{\circ} \mathrm{C}$. All the individual FAME compounds were identified by comparing the chromatograms of the obtained samples with the obtained chromatogram for the Standard 37 Component FAME mix, presented in Fig. 2, using the same operational conditions and the same equipment.

After identification of the compounds in the samples by GC analysis, the FAME content was determined by equation (3).<smiles>CCCCCCCCCCCC=CCCC(=O)OC</smiles>

Fig. 1. Esterification reaction of oleic acid. 


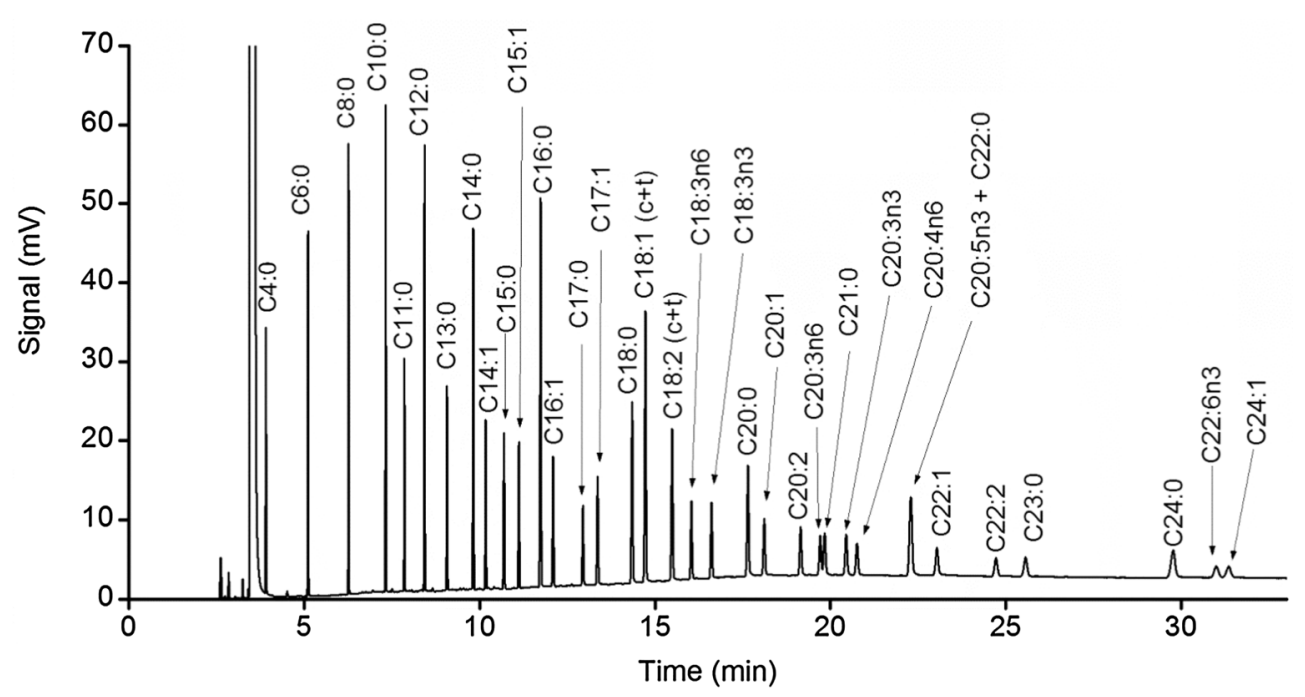

Fig. 2. Chromatogram of the 37 Component FAME mix obtained using the Varian GC-FID equipment with a Supelcowax10 column.

$C(\%)=\frac{\left(\sum A_{\text {FAMES }}-A_{I S}\right)}{A_{I S}} \times \frac{m_{I S}}{m_{\text {biodiesel }}} \times 100$

where $\Sigma A_{F A M E S}$ is the total peak area from FAME C14:0 to C24:1, $A_{I S}$ is the area of the heptadecanoic acid methyl ester compound, used as internal standard, $m_{I S}$ is the mass, in $\mathrm{mg}$, of the internal standard, and $m_{\text {biodiesel }}$ is the mass, in $\mathrm{mg}$, of the biodiesel sample.

In Fig. 3 (a) is presented the analysis performed to characterize quantitative and qualitatively the oleic acid sample, employed as raw material for the esterification reaction. The oleic acid contains mainly the methyl esters C16:0 (Palmitic, 1.6\%), C18:0 (Stearic, 2.8\%), C18:1 (Oleic, 87.3\%) and C18:2 (Linoleic, 4.6\%). Fig. 3 (b) is an example on the identification of the mentioned compounds, in a biodiesel sample, by comparing with the retention times observed in the analysis of the 37 FAME standard mix, as displayed in Fig. 2.

\subsection{Experimental design used for optimal conditions determination}

A response surface methodology known as Box-Behnken Design (BBD) was applied in order to evaluate the influence of four factors in the response. The chosen factors where reaction time (A), reaction temperature (B), methanol to oleic acid molar ratio (C) and catalyst dosage (D). Based on BBD, each factor was varied in different 3 levels $(-1,0$ and +1$)$ with the correspondent experimental values, as
Table 1

Factors and levels for the experimental design.

\begin{tabular}{|c|c|c|c|c|}
\hline \multirow[t]{2}{*}{ Factor } & \multirow[t]{2}{*}{ Code } & \multicolumn{3}{|c|}{ Level } \\
\hline & & -1 & 0 & +1 \\
\hline Time (h) & A & 4 & 6 & 8 \\
\hline Temperature $\left({ }^{\circ} \mathrm{C}\right)$ & $\mathrm{B}$ & 80 & 95 & 110 \\
\hline Molar ratio methanol/oleic acid & $\mathrm{C}$ & $5: 1$ & $10: 1$ & $15: 1$ \\
\hline Catalyst dosage (wt $\%)$ & $\mathrm{D}$ & 5 & 10 & 15 \\
\hline
\end{tabular}

presented in Table 1, generating a total of 27 experiments.

Each experiment was carried out accordingly to the general esterification procedure, described in Section 2.2. Two responses were evaluated: the conversion based on acid value, accordingly to Eqs. (1) and (2), and the FAME content, through gas chromatography analysis and accordingly to the Eq. (3). The quality of the model proposed and the effect of the factors on the responses was evaluated by Analysis of Variance (ANOVA).

\subsection{Kinetics study}

The esterification reaction of the oleic acid with methanol, (a)

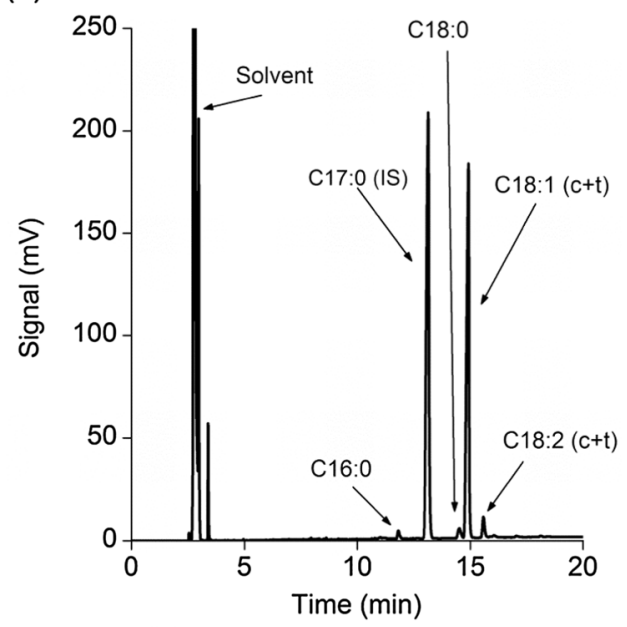

(b)

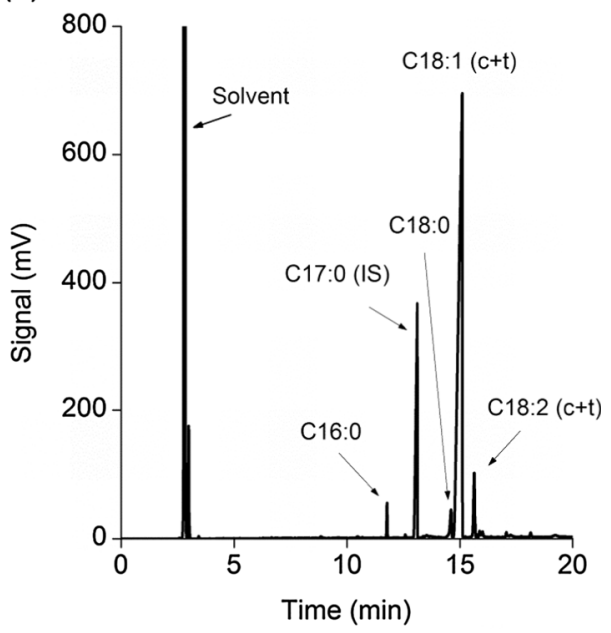

Fig. 3. (a) GC chromatogram for the characterization of the oleic acid sample, completely converted to methyl esters by derivatization with $\mathrm{BF}_{3}$ and (b) $\mathrm{GC}$ chromatogram of a biodiesel sample (Conditions: $110^{\circ} \mathrm{C}, 8 \mathrm{~h}, 14: 1 \mathrm{M}$ ratio methanol/oleic acid and $13.5 \mathrm{wt} \%$ catalyst dosage, leading to a $93.5 \%$ conversion and FAME content of $90.3 \%$ ). 
presented in Fig. 1, has a reaction rate that can be described by the Eq. (4).

- $r_{O A}=k_{1} C_{O A}{ }^{\alpha} C_{M e O H}{ }^{\beta}-k_{2} C_{F A M E}^{\gamma} C_{\text {water }}^{\delta}$

This equation can be simplified by making some assumptions: (i) the reaction is carried out under an excess of methanol, thus, its concentration can be assumed constant throughout the reaction and (ii) due to the excess of methanol, the equilibrium is highly shifted towards products formation, and the inverse reaction can be neglected. So, the reaction rate assumes the form of Eq. (5).

$-r_{O A}=k_{1}^{\prime} C_{O A}^{\alpha}$

With $\alpha$ being the reaction order related to oleic acid. To measure its value, a set of experiments was carried out under the following conditions, obtained from the optimization procedure: $15 \mathrm{wt} \%$ catalyst dosage, 15:1 methanol/oleic acid molar ratio and 8 hour reaction time. The temperature was varied in each experiment $(110,100,90,80$ and $70{ }^{\circ} \mathrm{C}$ ) and a sample was collected from the reaction vessel at pre-determined times. The acid value of each sample was determined and the conversion was estimated, according to Eqs. (1) and (2). The order of the reaction was determined by applying the integral method. Eq. (5) was integrated with $\alpha$ equal to $0,1,2$ and 3, giving origin to Eqs. (6) through (9).

0th order: $C_{O A}=C_{O A ; 0}-k_{1}^{\prime} t$

1st order: $\ln C_{O A}=\ln C_{O A ; 0}-k_{1}^{\prime} t$

2nd order: $1 / C_{O A}=1 / C_{O A ; 0}+k_{1}^{\prime} t$

3rd order: $1 / C_{O A}^{2}=1 / C_{O A ; 0}^{2}+2 k_{1}^{\prime} t$

The data were plotted accordingly to each equation. A straight line was expected and the curve that resulted in the highest coefficient of determination $\left(R^{2}\right)$ was assumed to be the apparent order of the reaction in relation to oleic acid.

\subsection{Characterization of biodiesel samples}

A FT-IR analysis was conducted in order to confirm qualitatively the esterification reaction of oleic acid to biodiesel. All spectra were obtained on ABB Inc., FTIR model MB3000, (Quebec, Canada) in transmittance mode by using a Miracle single reflection horizontal ATR accessory from Pike Technologies (Madison, WI, USA). Spectra were recorded between 650 and $4000 \mathrm{~cm}^{-1}$ at a resolution of $16 \mathrm{~cm}^{-1}$ and cumulative 32 scans. The FTIR data were acquired using the software Horizon MB v.3.4.

\section{Results and discussion}

\subsection{Selection of a suitable ionic liquid}

The first task was to investigate the catalytic activity of a few ionic liquids. Each run was carried out under the same experimental conditions: $6 \mathrm{~h}, 90 \pm 2{ }^{\circ} \mathrm{C}$, a catalyst dosage of $10 \mathrm{wt} \%$ and methanol/oleic acid ratio of 10:1 mol/mol. The ionic liquids comparison was based in the same imidazole cation group and varying different anion groups. The obtained results of the oleic acid conversion using five ionic liquids are presented in Fig. 4. The catalytic activity followed the order: 1-methylimidazolium hydrogen sulfate ([HMIM]HSO$\left.)_{4}\right) 2>1$-butyl-3-methylimidazolium methyl sulfate ([BMIM]MeSO$)_{4} 1>1$-butyl-3-methylimidazolium hydrogen sulfate ([BMIM] $\left.\mathrm{HSO}_{4}\right) 3>1$-butyl-3-methylimidazolium methanesulfonate ([BMIM] $\mathrm{CH}_{3} \mathrm{SO}_{3}$ ) $4>$ Tributylmethylammonium methyl sulfate $\left([T B M A] \mathrm{MeSO}_{4}\right)$ 5. Comparing the results observed with ionic liquids $\mathbf{1}$, 3 and 4, it is clear that the anion influences the ability of the ionic liquid to catalyze the reaction, with the anion acidity following the order $\left[\mathrm{MeSO}_{4}\right]^{-}>\left[\mathrm{HSO}_{4}\right]^{-}>\left[\mathrm{CH}_{3} \mathrm{SO}_{3}\right]^{-}$. For the cation, the order of strength is $[\mathrm{HMIM}]^{+}>[\mathrm{BMIM}]^{+}>[\mathrm{TBMA}]^{+}$. Therefore, the ionic

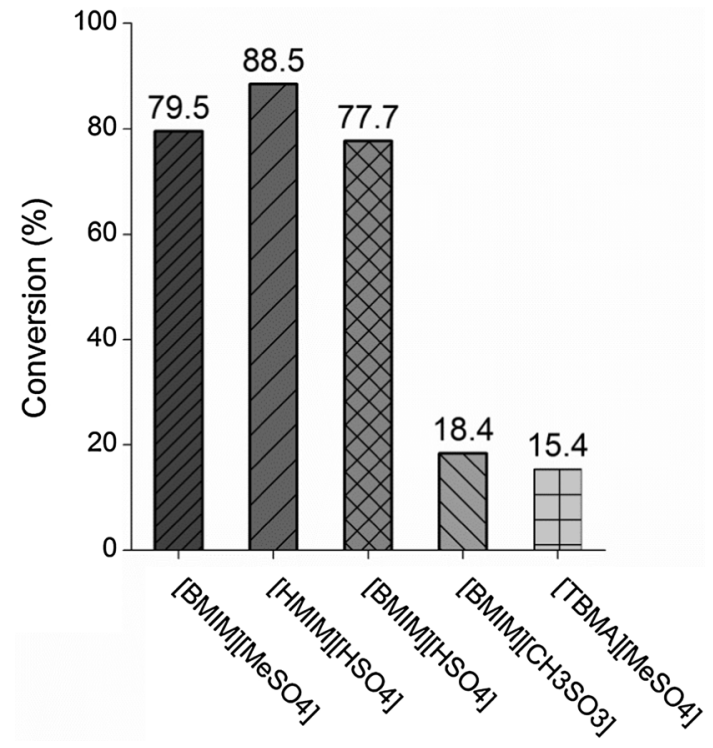

Fig. 4. Catalyst screening: comparison of the conversion of oleic acid obtained with different ionic liquids under the same reaction conditions $\left(6 \mathrm{~h}, 90 \pm 2{ }^{\circ} \mathrm{C}\right.$, molar ratio 10:1 and catalyst dosage $10 \mathrm{wt} \%$ ).

liquid 1-methylimidazolium hydrogen sulfate ([HMIM]HSO ${ }_{4}$ ) 2 was chosen for further studies.

\subsection{Response surface methodology results}

As described before, in Section 2.5, the response surface methodology chosen was the Box-Behnken Design (BBD) and 4 parameters (process variables), that were varied in 3 levels, were studied: time (A), temperature (B), molar ratio between oleic acid and methanol (C) and

Table 2

Experimental design, real conditions, conversion of oleic acid and FAME content $(\mathrm{A}=$ time; $\mathrm{B}=$ temperature; $\mathrm{C}=$ molar ratio $\mathrm{MeOH} / \mathrm{OA} ; \mathrm{D}=$ catalyst dosage).

\begin{tabular}{|c|c|c|c|c|c|c|}
\hline \multirow[t]{2}{*}{ Run } & \multicolumn{4}{|c|}{ Experimental Design } & \multicolumn{2}{|c|}{ Experimental Responses } \\
\hline & A & B & $\mathrm{C}$ & $\mathrm{D}$ & FAME content $(\%)$ & Conversion (\%) \\
\hline 1 & -1 & 1 & 0 & 0 & 82.8 & 83.8 \\
\hline 2 & -1 & 0 & 0 & -1 & 74.2 & 78.5 \\
\hline 3 & 0 & 0 & 0 & 0 & 85.0 & 88.6 \\
\hline 4 & -1 & 0 & -1 & 0 & 65.9 & 73.4 \\
\hline 5 & 0 & -1 & 1 & 0 & 85.5 & 89.6 \\
\hline 6 & 0 & 1 & 0 & 1 & 86.8 & 90.5 \\
\hline 7 & 0 & 1 & 1 & 0 & 87.5 & 92.2 \\
\hline 8 & 0 & 1 & 0 & -1 & 78.0 & 79.5 \\
\hline 9 & 0 & -1 & -1 & 0 & 72.6 & 77.2 \\
\hline 10 & 1 & 1 & 0 & 0 & 88.0 & 90.4 \\
\hline 11 & 1 & 0 & -1 & 0 & 74.4 & 77.3 \\
\hline 12 & -1 & 0 & 1 & 0 & 84.6 & 84.6 \\
\hline 13 & 0 & -1 & 0 & -1 & 77.7 & 82.8 \\
\hline 14 & 0 & 0 & 1 & 1 & 87.4 & 92.5 \\
\hline 15 & 0 & 0 & 1 & -1 & 78.7 & 82.4 \\
\hline 16 & 1 & 0 & 0 & -1 & 80.4 & 84.3 \\
\hline 17 & 1 & -1 & 0 & 0 & 86.0 & 90.9 \\
\hline 18 & 0 & 1 & -1 & 0 & 68.4 & 74.5 \\
\hline 19 & 0 & 0 & 0 & 0 & 84.6 & 89.2 \\
\hline 20 & -1 & -1 & 0 & 0 & 81.4 & 83.5 \\
\hline 21 & 0 & 0 & 0 & 0 & 85.5 & 88.3 \\
\hline 22 & -1 & 0 & 0 & 1 & 81.7 & 83.4 \\
\hline 23 & 1 & 0 & 0 & 1 & 87.0 & 90.5 \\
\hline 24 & 1 & 0 & 1 & 0 & 90.2 & 92.8 \\
\hline 25 & 0 & -1 & 0 & 1 & 84.5 & 89.3 \\
\hline 26 & 0 & 0 & -1 & 1 & 73.3 & 74.8 \\
\hline 27 & 0 & 0 & -1 & -1 & 64.4 & 71.9 \\
\hline
\end{tabular}


Table 3

ANOVA table for the FAME content $(\mathrm{A}=$ time; $\mathrm{B}=$ temperature; $\mathrm{C}=$ molar ratio $\mathrm{MeOH} / \mathrm{OA}$; $\mathrm{D}=$ catalyst dosage).

\begin{tabular}{llllll}
\hline Source & $\begin{array}{l}\text { Sum of } \\
\text { squares }\end{array}$ & Df & $\begin{array}{l}\text { Mean } \\
\text { Square }\end{array}$ & F-value & p-Value \\
\hline Model & 1319.90 & 14 & 94.28 & 72.920 & $2.14 \mathrm{E}-09$ \\
A-Time & 115.38 & 1 & 115.38 & 89.240 & $6.61 \mathrm{E}-07$ \\
B-Temperature & 2.18 & 1 & 2.18 & 1.690 & 0.2181 \\
C- Molar ratio MeOH/ & 750.34 & 1 & 750.34 & 580.340 & $1.56 \mathrm{E}-11$ \\
$\quad$ OA & & & & & \\
D- Catalyst dosage & 192.96 & 1 & 192.96 & 149.240 & $3.95 \mathrm{E}-08$ \\
AB & 0.0841 & 1 & 0.0841 & 0.065 & 0.8030 \\
AC & 2.07 & 1 & 2.07 & 1.600 & 0.2294 \\
AD & 0.2352 & 1 & 0.2352 & 0.182 & 0.6773 \\
BC & 9.61 & 1 & 9.61 & 7.430 & 0.0184 \\
BD & 0.1681 & 1 & 0.1681 & 0.130 & 0.7247 \\
CD & 0.0006 & 1 & 0.0006 & 0.001 & 0.9828 \\
A $^{2}$ & 0.8129 & 1 & 0.8129 & 0.629 & 0.4432 \\
$\mathrm{~B}^{2}$ & 0.1070 & 1 & 0.1070 & 0.083 & 0.7785 \\
$\mathrm{C}^{2}$ & 197.51 & 1 & 197.51 & 152.760 & $3.48 \mathrm{E}-08$ \\
$\mathrm{D}^{2}$ & 48.78 & 1 & 48.78 & 37.730 & $5.01 \mathrm{E}-05$ \\
Residual & 15.52 & 12 & 1.29 & & \\
Lack of Fit & 15.12 & 10 & 1.51 & 7.63 & 0.1213 \\
Pure Error & 0.3961 & 2 & 0.1980 & & \\
Cor Total & 1335.41 & 26 & & & \\
$\mathrm{R}^{2}=0.9884$ & Adj $\mathrm{R}^{2}=0.9748$ & & & \\
\hline
\end{tabular}

the catalyst dosage (D). The 27 experimental runs design and the corresponding responses are presented in Table 2. Two responses were evaluated: the FAME content, determined by gas chromatography and the conversion of the reactant (oleic acid), determined by comparing the initial and final acid values of the samples.

In general, it was observed that the most relevant factors for both responses studied were the molar ratio between oleic acid and methanol and the catalyst dosage, followed by time. The variable temperature did not have a significant influence.

\subsubsection{Analysis regarding the FAME content}

The quadratic equation that best fits the data obtained for the FAME content is represented by Eq. (10). The statistical analysis indicates that the model is reasonable and statistically significant, with a $\mathrm{R}^{2}=0.9884$, indicating that the experimental and the predicted values are very close. The results were evaluated by the Analysis of Variance (ANOVA), displayed in Table 3.

$$
\begin{aligned}
Y= & 85.01+3.10 A+0.43 B+7.91 C+4.01 D-0.39 A^{2}-0.14 B^{2}-6.09 C^{2} \\
& -3.02 D^{2}+0.145 A B-0.72 A C+0.24 A D+1.55 B C+0.21 B D \\
& -0.0125 C D
\end{aligned}
$$

The high F-value encountered in the ANOVA table indicates that the model is significant for the response evaluated. Additionally, the ANOVA specifies which of the factors are relevant. A p-value lower than 0.05 indicates a significant factor, while a $p$-value higher than 0.1 indicates an irrelevant factor. For the current analysis, the factors A, C, D, $\mathrm{BC}, \mathrm{C}^{2}$ and $\mathrm{D}^{2}$ are all relevant parameters for the FAME content. The remaining factors are not relevant. Also, the lower the $p$-value is, the most influential such factor is on the response. The lowest $p$-values encountered are related to the molar ratio effect (C) and the catalyst dosage effect (D).

Fig. 5 displays the contour plots for all interactions between factors and their effect on the response. The variables not displayed on each plot were set at their center value (0). Fig. 5 (a) displays the interaction of time and temperature. Moving along the temperature axis does not alter the response, restating the lack of influence of this variable. Fig. 5 (b) displays the interaction of time and molar ratio. The plot reinforces the idea that molar ratio is the most relevant variable, as moving along its axis results in an alteration in the FAME content from $70 \%$ to over $85 \%$. Fig. 5 (c) displays the interaction of time and catalyst dosage. Both variables have a significant influence on the response. Fig. 5 (d) displays the interaction between temperature and molar ratio. The temperature does not have a significant effect on the response, and the molar ratio has a very strong effect. In addition, the ANOVA table states a $p$-value for the interaction of those factors of 0.0184 , meaning that their interaction is relevant. The presumed reason is that the increase in temperature leads to a greater rate of methanol evaporation, changing its quantity constantly during the reaction, and therefore the change in temperature has a direct influence in the molar ratio between methanol and oleic acid. Fig. 5 (e) displays the interaction of temperature and catalyst dosage. The variable temperature is clearly not relevant. Fig. 5 (f) displays the interaction of the two most relevant factors: molar ratio and catalyst dosage. The contour plot reinforces the influence of those variables: the combination in their lower bound $(-1)$ leads to a FAME content lower than $70 \%$, while their combination in their upper bound $(+1)$ leads to a content close to $90 \%$.

Maximizing Eq. (10) leads to the optimal values of each parameter that results in the highest FAME content, displayed in Table 4. Three confirmation runs were performed. The predicted response was a FAME content of $92.9 \%$, ranging from 90.1 to $95.8 \%$ and the average of the confirmation runs was $90.5 \%$. This value allows concluding that the developed model was able to accurately predict the response and it is well fitted to the experimental data.

The optimal conditions obtained and presented in Table 4 show that increasing the value of time and temperature has a positive effect on the FAME content. However, this effect is not so clear for molar ratio and catalyst dosage, because the maximum FAME content is predicted for an intermediate coded value.

\subsubsection{Analysis regarding the conversion of oleic acid}

The quadratic equation that best fits the experimental data obtained for the conversion of oleic acid is represented by Eq. (11). The statistical analysis indicates that the model is reasonable and statistically significant, with a $\mathrm{R}^{2}=0.9925$.

$$
\begin{aligned}
Y= & 88.68+3.25 A-0.21 B+7.08 C+3.47 D-1.44 A^{2}-0.095 B^{2} \\
& -5.21 C^{2}-3.09 D^{2}-0.20 A B+1.11 A C+0.35 A D+1.32 B C \\
& +1.13 B D+1.81 C D
\end{aligned}
$$

The high F-value indicates a good model for the conversion of oleic acid. In this case, the relevant factors are A, C, D, AC, BC, BD, CD, $\mathrm{A}^{2}, \mathrm{C}^{2}$ and $\mathrm{D}^{2}$, as appointed by Table 5 . The remaining factors are not relevant. The most significant factors are the molar ratio and the catalyst dosage.

Fig. 6 displays the contour plots for the all the variables and their effect on the conversion of oleic acid. The analysis is very similar to the one presented for the FAME content. Fig. 6 (a) presents the influence of variables time and temperature on the conversion, while Fig. 6 (b), the effect of time and molar ratio, and Fig. 6 (c), the effect of time and catalyst dosage. The mentioned plots allow concluding that the variables significance follows the order: molar ratio, catalyst dosage, time and lastly, temperature. Fig. 6 (d) displays the influence of temperature and molar ratio, and as in the previous analysis for the FAME content, the interaction between the variables is statistically significant, with a p-value of 0.0078. Fig. 6 (e) displays the interaction of variables temperature and catalyst dosage. There's a slight influence of the temperature on the catalyst dosage variable. Finally, Fig. 6 (f) presents the interaction between molar ratio and catalyst dosage. The two variables are clearly very relevant to the system.

Maximizing equation (11) lead to optimal values displayed in Table 6.

The predicted conversion was $97.9 \%$ for this condition (ranging from 95.0 to $100.8 \%$ ). The average conversion for the three 

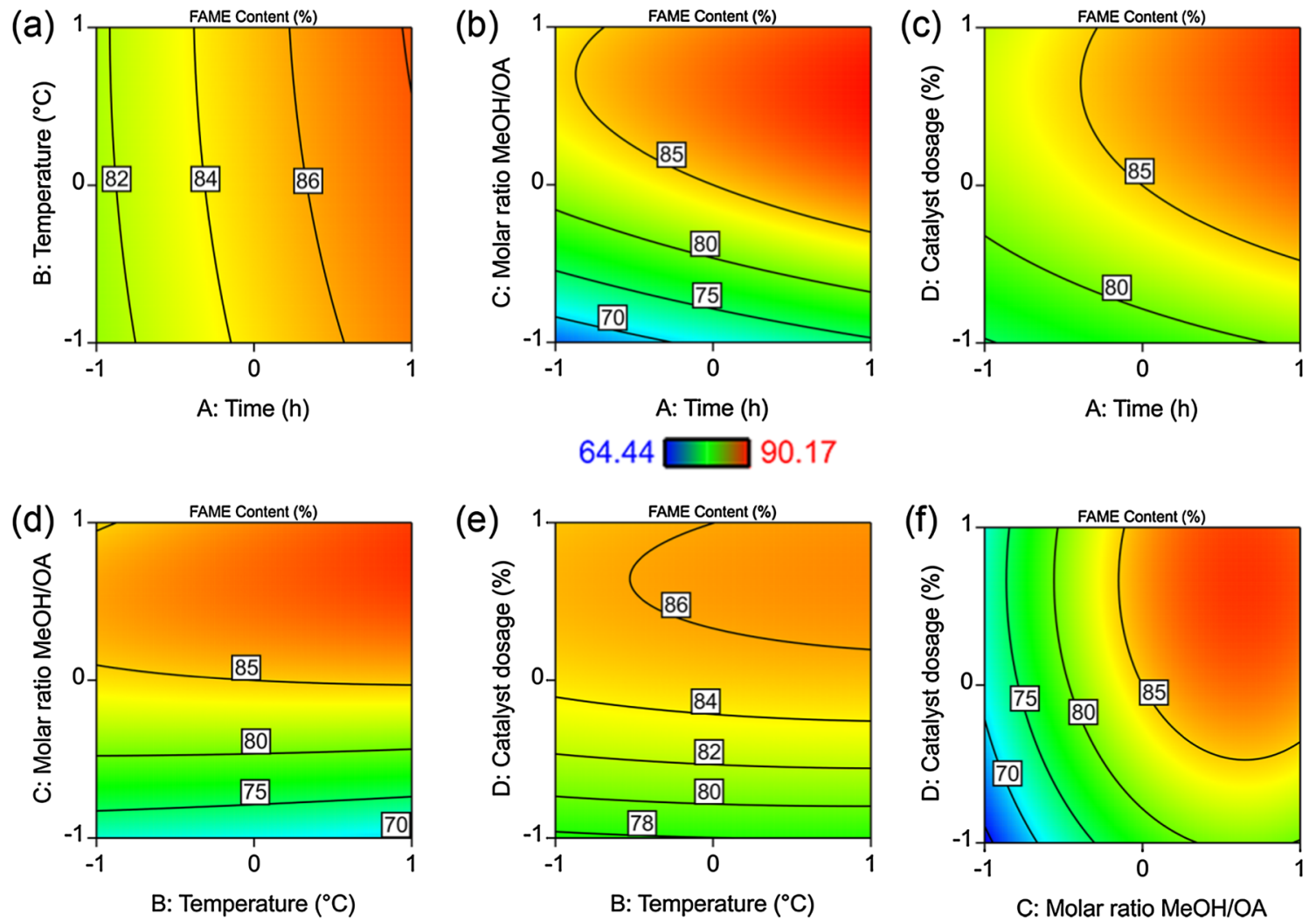

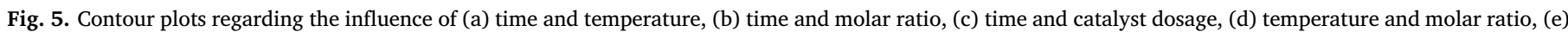
temperature and catalyst dosage, and (f) molar ratio and catalyst dosage on the FAME content of the biodiesel samples.

Table 4

Optimal conditions to obtain the highest FAME content.

\begin{tabular}{llll}
\hline Code & Factor & Coded Value & Real Value \\
\hline A & Time & 1.000 & $8 \mathrm{~h}$ \\
B & Temperature & 1.000 & $110^{\circ} \mathrm{C}$ \\
C & Molar Ratio MeOH/OA & 0.718 & $13.6: 1$ \\
D & Catalyst Dosage & 0.735 & $13.5 \mathrm{wt} \%$ \\
\hline
\end{tabular}

Table 5

ANOVA table for the conversion of oleic acid $(\mathrm{A}=$ time; $\mathrm{B}=$ temperature; $\mathrm{C}=$ molar ratio $\mathrm{MeOH} / \mathrm{OA} ; \mathrm{D}=$ catalyst dosage).

\begin{tabular}{llllll}
\hline Source & $\begin{array}{l}\text { Sum of } \\
\text { squares }\end{array}$ & Df & $\begin{array}{l}\text { Mean } \\
\text { Square }\end{array}$ & F-value & p-Value \\
\hline Model & 1085.81 & 14 & 77.56 & 112.74 & $1.64 \mathrm{E}-10$ \\
A-Time & 126.82 & 1 & 126.82 & 184.34 & $1.21 \mathrm{E}-08$ \\
B-Temperature & 0.5208 & 1 & 0.5208 & 0.7571 & 0.4013 \\
C- Molar ratio MeOH/ & 601.80 & 1 & 601.80 & 874.77 & $1.39 \mathrm{E}-12$ \\
$\quad$ OA & & & & & \\
D- Catalyst dosage & 144.84 & 1 & 144.84 & 210.53 & $5.68 \mathrm{E}-09$ \\
AB & 0.1600 & 1 & 0.1600 & 0.2326 & 0.6383 \\
AC & 4.95 & 1 & 4.95 & 7.20 & 0.0199 \\
AD & 0.4900 & 1 & 0.4900 & 0.7123 & 0.4152 \\
BC & 7.00 & 1 & 7.00 & 10.17 & 0.0078 \\
BD & 5.13 & 1 & 5.13 & 7.46 & 0.0182 \\
CD & 13.10 & 1 & 13.10 & 19.05 & 0.0009 \\
$\mathrm{~A}^{2}$ & 11.12 & 1 & 11.12 & 16.17 & 0.0017 \\
$\mathrm{~B}^{2}$ & 0.0486 & 1 & 0.0486 & 0.0706 & 0.7950 \\
$\mathrm{C}^{2}$ & 144.65 & 1 & 144.65 & 210.27 & $5.72 \mathrm{E}-09$ \\
$\mathrm{D}^{2}$ & 50.81 & 1 & 50.81 & 73.86 & $1.79 \mathrm{E}-06$ \\
Residual & 8.26 & 12 & 0.6880 & & \\
Lack of Fit & 7.86 & 10 & 0.7863 & 4.01 & 0.2162 \\
Pure Error & 0.3925 & 2 & 0.1962 & & \\
Cor Total & 1094.07 & 26 & & & \\
$\mathrm{R}^{2}=0.9925$ & Adj $\mathrm{R}^{2}=0.9837$ & & & \\
\hline & & & & & \\
\hline
\end{tabular}

confirmation runs was $95.3 \%$. This value is within the range predicted by the model, suggesting a well-adjusted model. The optimal conditions obtained and presented in Table 6 show that increasing the value of all of the factors has a positive effect on the reaction conversion.

\subsection{Kinetics study}

The study of the esterification reaction kinetics was performed as described in Section 2.6. A set of experiments was carried out using the optimized conditions for the conversion: $15 \mathrm{wt} \%$ catalyst dosage, a methanol/oleic acid molar ratio of $15: 1$, a reaction time of $8 \mathrm{~h}$ and the reaction temperature was varied in each experiment $(110,100,90,80$ and $70{ }^{\circ} \mathrm{C}$ ). During each experiment several samples were collected at different reaction times (from 0 to $480 \mathrm{~min}$ ). The obtained conversion results and acid values and are presented in Fig. 7 (a) and (b) respectively.

Then, the order of the reaction was determined using the integral method and the obtained data were plotted considering the reaction order of $0,1,2$ and 3 . The highest coefficient of determination, displayed in Table 7 for all temperatures, was found for the reaction rate following 3rd order kinetics. Table 7 also displays the $k^{\prime}{ }_{1}$ obtained for each temperature. The $k^{\prime}{ }_{1}$ and the temperature are correlated by the Arrhenius law, given by Eq. (12).

$k_{1}^{\prime}=k_{0} \exp \frac{-E_{a}}{R T}$

Applying the logarithm to Eq. (12) leads to its linearization, and therefore, by plotting the experimental data, the kinetic parameters activation energy $\left(E_{a}\right)$ and pre-exponential factor $\left(k_{0}\right)$ can be estimated.

Fig. 8 presents the plot of the inverse of the temperature and the natural logarithm of the kinetic constants. A coefficient of determination of $\mathrm{R}^{2}=0.96581$ was obtained and the pre-exponential factor $\left(k_{0}\right)$ was found as $0.0765 \mathrm{~L}^{2} \cdot \mathrm{mol}^{-2} \cdot \mathrm{min}^{-1}$ and the activation energy $\left(E_{a}\right)$ as $6.8 \mathrm{~kJ} / \mathrm{mol}$. The value found for the activation energy in our work is 

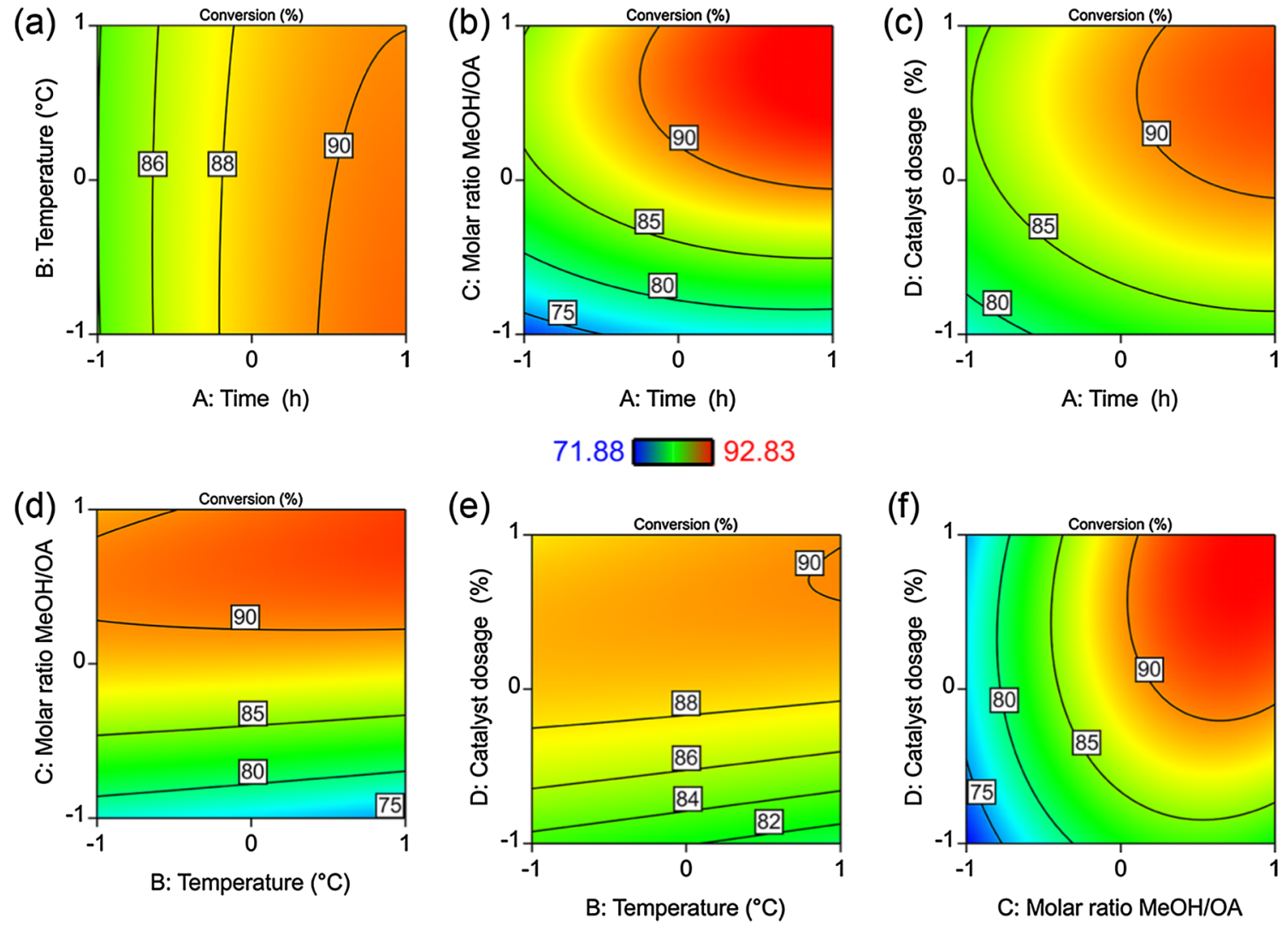

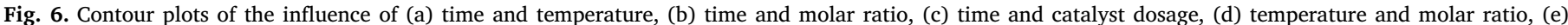
temperature and catalyst dosage and (f) molar ratio and catalyst dosage on the conversion of oleic acid.

Table 6

Optimal conditions to obtain the highest conversion of oleic acid.

\begin{tabular}{llll}
\hline Code & Factor & Coded Value & Real Value \\
\hline A & Time & 1.000 & $8 \mathrm{~h}$ \\
B & Temperature & 0.999 & $110^{\circ} \mathrm{C}$ \\
C & Molar Ratio MeOH/OA & 0.999 & $15: 1$ \\
D & Catalyst Dosage & 0.999 & $15 \mathrm{wt} \%$ \\
\hline
\end{tabular}

(a)

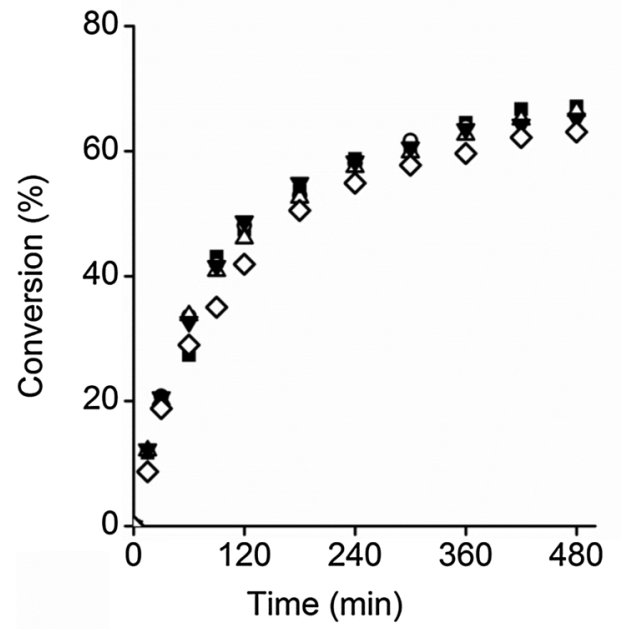

much lower than the values determined in other works $[5,24-26]$ for similar systems.

Table 8 presents a summary of those studies regarding the determination of kinetic parameters using acidic catalysts for esterification reactions. The value estimated for the activation energy is lower than the values found in literature, except for the study done by Aranda et al. [27]. They studied the esterification reaction of palm fatty acids with methanol using acidic catalysts. Sulfuric acid and methanesulfonic acid presented the best activity and they investigated the influence of

(b)

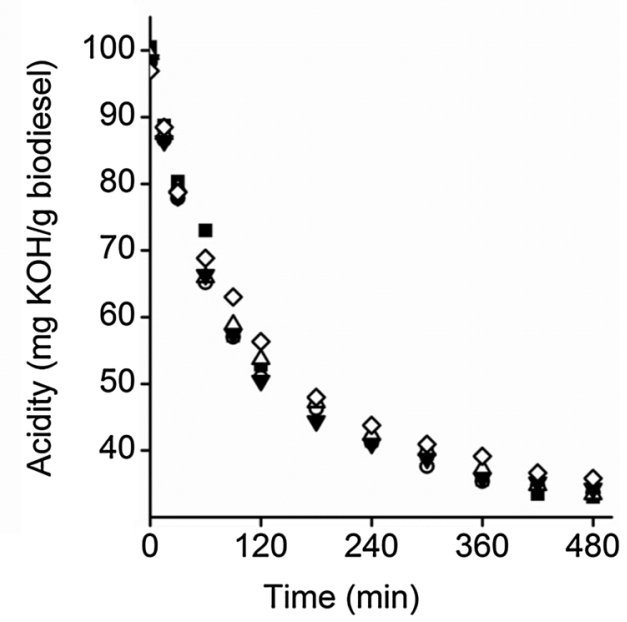

- $110^{\circ} \mathrm{C} \circ 100^{\circ} \mathrm{C} \Delta 90^{\circ} \mathrm{C} \nabla 80^{\circ} \mathrm{C} \diamond 70^{\circ} \mathrm{C}$

Fig. 7. (a) Conversion of the oleic acid for each sample versus time and (b) Acidity of the reaction samples versus time, studied for five different reaction temperatures.(Conditions: 15:1 $\mathrm{M}$ ratio methanol/oleic acid, $15 \mathrm{wt} \%$ catalyst dosage, $8 \mathrm{~h}$ reaction time). 
Table 7

Kinetics constants and coefficient of determination obtained for each reaction temperature.

\begin{tabular}{lll}
\hline Temperature $\left({ }^{\circ} \mathrm{C}\right)$ & $k^{\prime}{ }_{1}\left(\mathrm{~L}^{2} \cdot \mathrm{mol}^{-2} \cdot \mathrm{min}^{-1}\right)$ & $\mathrm{R}^{2}$ \\
\hline 110 & 0.009135 & 0.99502 \\
100 & 0.008265 & 0.98132 \\
90 & 0.008045 & 0.99457 \\
80 & 0.007595 & 0.96825 \\
70 & 0.007000 & 0.99089 \\
\hline
\end{tabular}

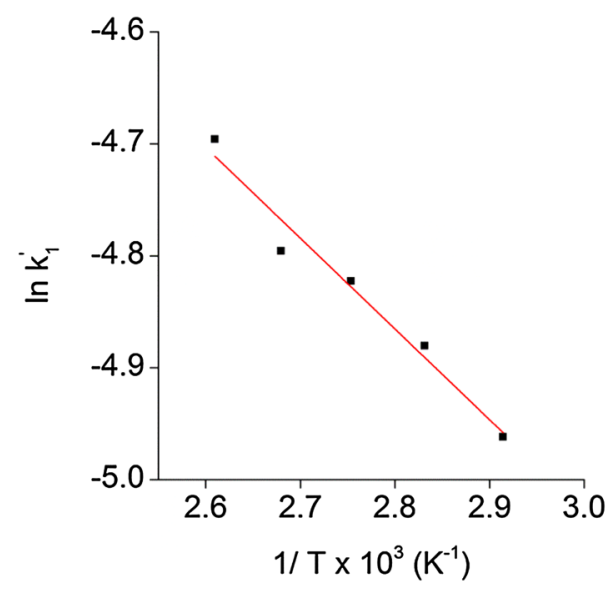

Fig. 8. Arrhenius plot for the reaction rate $k_{1}^{\prime}$ with temperature ranging from $110^{\circ} \mathrm{C}$ to $70^{\circ} \mathrm{C}$.

varying the catalyst concentration in the activation energy. The main conclusion was that increasing the catalyst dosage, the activation energy decreases. Even though they have observed activation energies as low as $6.53 \mathrm{~kJ} / \mathrm{mol}$ for sulfuric acid and $3.78 \mathrm{~kJ} / \mathrm{mol}$ for methanesulfonic acid, values below the one observed in our study, the ionic liquid presents the advantage of being environmentally friendly, as well as presenting the important advantage of recovery and recyclability.

The low activation energy points this catalyst as very suitable for replacement of traditional acidic catalysts and it agrees with the results obtained in the experimental design, by reinforcing the idea that the temperature is not a very dominant factor for the esterification reaction applying the catalyst 1-methylimidazolium hydrogen sulfate.

\subsection{Characterization of biodiesel samples}

FT-IR analysis was done to ensure that the oleic acid (carboxylic acid) was being converted into FAMEs (esters). Fig. 9 displays (a) oleic acid sample and (b) biodiesel (FAME). The oleic acid sample presents a broad and strong band, from 3300 to $2500 \mathrm{~cm}^{-1}$ and centered at $3000 \mathrm{~cm}^{-1}$, and highlighted with a solid circle in the spectrum. This band is associated to the $\mathrm{O}-\mathrm{H}$ stretching and it is a characteristic band of a carboxylic acids. This band also overlaps with the bands corresponding to the asymmetric and symmetric stretching of the $\mathrm{CH}_{2}$ groups, appearing at $2924 \mathrm{~cm}^{-1}$ and $2855 \mathrm{~cm}^{-1}$ respectively. The bands at $2650 \mathrm{~cm}^{-1}$ and $2545 \mathrm{~cm}^{-1}$ are also in the previously referred overtone region and are a characteristic pattern for a $\mathrm{COOH}$ group. The most strong and sharp band, highlighted with a dashed rectangle, visible at $1705 \mathrm{~cm}^{-1}$, is ascribed to the $\mathrm{C}=\mathrm{O}$ stretching of a dimer in the carboxylic acid, such as the oleic acid. The band at $1458 \mathrm{~cm}^{-1}$ is representative of the asymmetric bend of the $\mathrm{CH}_{3}$ group and the $1410 \mathrm{~cm}^{-1}$ band is related with the $\mathrm{CH}_{2}$ bend, normally called as the "scissors" bend. Both $1288 \mathrm{~cm}^{-1}$ and $1242 \mathrm{~cm}^{-1}$ band are related with the stretch and bend in the $\mathrm{COOH}$ group. They result from a combination of $\mathrm{O}-\mathrm{C}-\mathrm{O}$ asymmetric stretch and $\mathrm{OH}$ bend. The band at $933 \mathrm{~cm}^{-1}$ is characteristic of the dimeric oleic acid and results from an angular deformation outside the plan of $\mathrm{O}-\mathrm{H}$ bond. The band at $725 \mathrm{~cm}^{-1}$ is ascribed to the concerted rocking of all $\mathrm{CH}_{2}$ groups in the chain of four or more. Both bands highlighted in the spectrum are the main ones that allow concluding the presence of a carboxylic acid.

The infrared spectrum of the biodiesel sample, presented in Fig. 9 (b), shows very similar bands, but a few changes are noticeable. The broad and strong band, from 3300 to $2500 \mathrm{~cm}^{-1}$ and centered at $3000 \mathrm{~cm}^{-1}$ and highlighted with a solid circle in the spectrum has disappeared. The sharp and strong band related to the stretching of the $\mathrm{C}=\mathrm{O}$ bond in the carbonyl group of esters and highlighted with a dashed rectangle moved to $1744 \mathrm{~cm}^{-1}$. In the biodiesel sample a new broad and strong band centered at $1172 \mathrm{~cm}^{-1}$ is highlighted with a dotted rectangle, is ascribed to the absorption of the stretching of the $\mathrm{C}-\mathrm{O}$ bond existing in esters. The two mentioned bands are the main ones that define an ester in an infrared spectrum.

\section{Conclusions}

The chosen catalyst 1-methylimidazolium hydrogen sulfate [HMIM] $\mathrm{HSO}_{4}$ has displayed a very good catalytic activity in the conversion of oleic acid into FAMEs, and therefore seems a suitable and promising catalyst in the context of biodiesel production, namely for the treatment of highly acidic oils, such as waste cooking oils. Further studies are still necessary to determine its applicability in the transesterification reaction. The optimal condition for the conversion of oleic acid was determined as being $8 \mathrm{~h}, 110^{\circ} \mathrm{C}, 15: 1 \mathrm{M}$ ratio of methanol to oleic acid and a $15 \mathrm{wt} \%$ catalyst loading, leading to a conversion of $95.9 \%$, while for the FAME content, determined by gas chromatography, it was determined as $8 \mathrm{~h}, 110^{\circ} \mathrm{C}, 13.6: 1 \mathrm{M}$ ratio of methanol to oleic acid and a $13.5 \mathrm{wt} \%$ catalyst loading, leading to a content of $90.5 \%$. Moreover, the determination of the kinetics constants reiterates the applicability of the ionic liquid, with an activation energy of $6.8 \mathrm{~kJ} / \mathrm{mol}$. The observed value is lower than the activation energy appointed in the literature for commonly used catalysts for biodiesel production. In addition, the experimental design led to the conclusion that the temperature is an irrelevant factor, which is restated by the low activation energy.

Table 8

Activation energy values for several types of catalysts used in the esterification reaction of different feedstocks, found in some published works.

\begin{tabular}{|c|c|c|c|c|c|c|}
\hline Feedstock & Alcohol & Reaction Order & Catalyst & Temperature range $(\mathrm{K})$ & Activation Energy $(\mathrm{kJ} / \mathrm{mol})$ & Ref. \\
\hline Oleic acid & $\mathrm{MeOH}$ & 1 st & 1-butyl-3-methylimidazolium tetrachloroferrite & $313-343$ & 17.97 & {$[28]$} \\
\hline Waste plum stone & $\mathrm{MeOH}$ & 1 st & $\mathrm{H}_{2} \mathrm{SO}_{4}$ & $313-333$ & $13.20-11.55^{\mathrm{a}}$ & [29] \\
\hline Oleic acid & EtOH & 2nd & $\mathrm{H}_{2} \mathrm{SO}_{4}$ & $348-393$ & 36.62 & {$[5]$} \\
\hline Palm fatty acids & $\mathrm{MeOH}$ & 1 st & $\mathrm{H}_{2} \mathrm{SO}_{4}$ & $403-433$ & $6.53-15.05^{\mathrm{a}}$ & [27] \\
\hline Palm fatty acids & $\mathrm{MeOH}$ & $1 \mathrm{st}$ & $\mathrm{CH}_{3} \mathrm{SO}_{2} \mathrm{OH}$ & $403-433$ & $3.78-10.12^{\mathrm{a}}$ & [27] \\
\hline Palm oil & $\mathrm{MeOH}$ & 2nd & $\mathrm{H}_{2} \mathrm{SO}_{4}$ & $328-338$ & 75.3 & {$[30]$} \\
\hline Oleic acid & $\mathrm{MeOH}$ & 3rd & 1-methylimidazolium hydrogen sulfate & $343-383$ & 6.8 & this work \\
\hline
\end{tabular}

a Kinetics studies carried out with the variation in catalyst dosage and/or alcohol amount. 
(a)

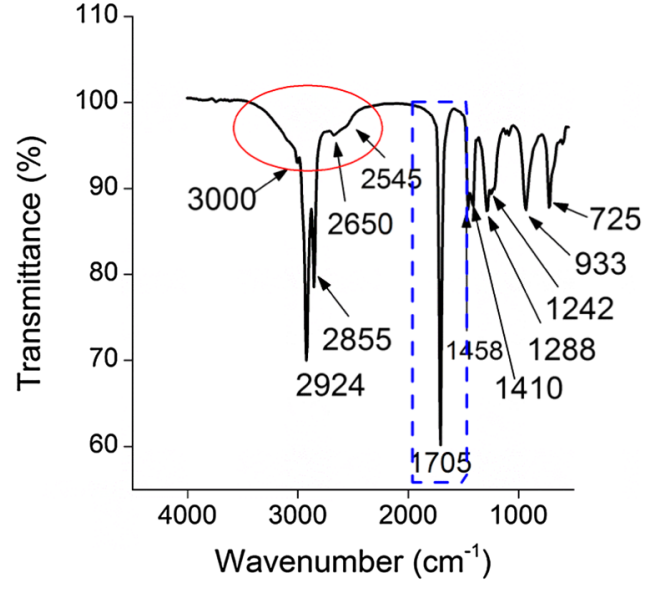

(b)

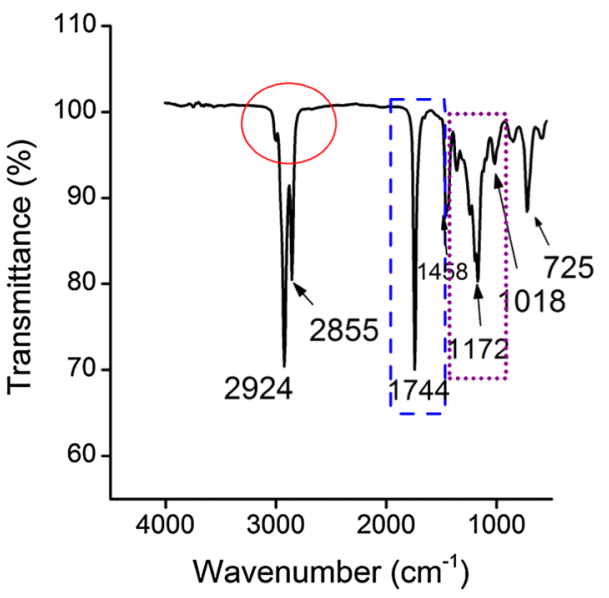

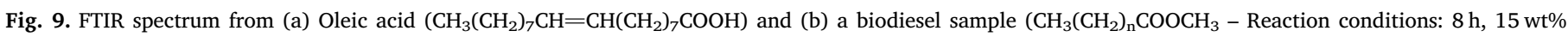
catalyst dosage, $15: 1$ methanol/oleic acid ratio and $\left.110{ }^{\circ} \mathrm{C}\right)$.

\section{Acknowledgments}

The authors hereby acknowledge Dr. Isabel Patrícia Fernandes and Prof. Dr. Filomena Barreiro, for the support provided regarding the FTIR analysis, and Eng. Cristiana Brás Meireles. Also, the authors express their gratitude to Instituto Politécnico de Bragança and Universidade Tecnológica Federal do Paraná.

\section{References}

[1] Mohamad M, Ngadi N, Wong SL, Jusoh M, Yahya NY. Prediction of biodiesel yield during transesterification process using response surface methodology. Fuel 2017;190:104-12. https://doi.org/10.1016/j.fuel.2016.10.123.

[2] Feng Y, Qiu T, Yang J, Li L, Wang X, Wang H. Transesterification of palm oil to biodiesel using Brønsted acidic ionic liquid as high-efficient and eco-friendly catalyst. Chin J Chem Eng 2017;25:1222-9. https://doi.org/10.1016/j.cjche.2017.06. 027.

[3] Ullah Z, Bustam MA, Man Z, Khan AS, Muhammad N, Sarwono A. Preparation and kinetics study of biodiesel production from waste cooking oil using new functionalized ionic liquids as catalysts. Renew Energy 2017;114:755-65. https://doi.org/ 10.1016/j.renene.2017.07.085.

[4] Hu S, Li Y, Lou W. Novel efficient procedure for biodiesel synthesis from waste oils with high acid value using 1-sulfobutyl-3-methylimidazolium hydrosulfate ionic liquid as the catalyst is. Chin J Chem Eng 2017;25:1519-23. https://doi.org/10. 1016/j.cjche.2017.03.029.

[5] Neumann K, Werth K, Martín A, Górak A. Biodiesel production from waste cooking oils through esterification: Catalyst screening, chemical equilibrium and reaction kinetics. Chem Eng Res Des 2016;107:52-62. https://doi.org/10.1016/j.cherd. 2015.11.008.

[6] Wu S, Song L, Sommerfeld M, Hu Q, Chen W. Optimization of an effective method for the conversion of crude algal lipids into biodiesel. Fuel 2017;197:467-73. https://doi.org/10.1016/j.fuel.2017.02.040.

[7] Guldhe A, Singh P, Ansari FA, Singh B, Bux F. Biodiesel synthesis from microalgal lipids using tungstated zirconia as a heterogeneous acid catalyst and its comparison with homogeneous acid and enzyme catalysts. Fuel 2017;187:180-8. https://doi. org/10.1016/j.fuel.2016.09.053.

[8] Dias JM, Alvim-Ferraz MCM, Almeida MF, Méndez Díaz JD, Polo MS, Utrilla JR. Selection of heterogeneous catalysts for biodiesel production from animal fat. Fuel 2012;94:418-25. https://doi.org/10.1016/j.fuel.2011.10.069.

[9] Islam A, Ravindra P. Biodiesel production with green technologies. Cham: Springer International Publishing; 2017. doi:10.1007/978-3-319-45273-9.

[10] Ramos LP, da Silva FR, Mangrich AS, Cordeiro CS. Tecnologias de Produção de Biodiesel. Rev Virtual Química 2011;3:385-405. https://doi.org/10.5935/19846835.20110043.

[11] Demirbas A. Importance of biodiesel as transportation fuel. Energy Policy 2007;35:4661-70. https://doi.org/10.1016/j.enpol.2007.04.003.

[12] Ishak ZI, Sairi NA, Alias Y, Aroua MKT, Yusoff R. A review of ionic liquids as catalysts for transesterification reactions of biodiesel and glycerol carbonate production. Catal Rev 2017;59:44-93. https://doi.org/10.1080/01614940.2016.1268021.

[13] Yusuf NNAN, Kamarudin SK, Yaakub Z. Overview on the current trends in biodiesel production. Energy Convers Manag 2011;52:2741-51. https://doi.org/10.1016/j. enconman.2010.12.004.

[14] Fang Z. Biodiesel - feedstocks, production and applications. InTech 2012. https:// doi.org/10.5772/45895.

[15] Fan P, Xing S, Wang J, Fu J, Yang L, Yang G, et al. Sulfonated imidazolium ionic liquid-catalyzed transesterification for biodiesel synthesis. Fuel 2017;188:483-8. https://doi.org/10.1016/j.fuel.2016.10.068

[16] Rafiee E, Mirnezami F. Temperature regulated Brønsted acidic ionic liquid-catalyze esterification of oleic acid for biodiesel application. J Mol Struct 2017;1130:296-302. https://doi.org/10.1016/j.molstruc.2016.10.049.

[17] Mai NL, Ahn K, Koo Y-M. Methods for recovery of ionic liquids-A review. Process Biochem 2014;49:872-81. https://doi.org/10.1016/j.procbio.2014.01.016.

[18] Krossing I, Slattery JM, Daguenet C, Dyson PJ, Oleinikova A, Weingä H. Why Are Ionic Liquids Liquid? A Simple Explanation Based on Lattice and Solvation Energies 2006. doi:10.1021/ja0619612.

[19] Zhao H, Baker GA. Ionic liquids and deep eutectic solvents for biodiesel synthesis: a review. J Chem Technol Biotechnol 2013;88:3-12. https://doi.org/10.1002/jctb. 3935.

[20] Hardacre C, Parvulescu V. Catalysis in ionic liquids: from catalysts synthesis to application. Cambridge: The Royal Society of Chemistry; 2014. doi: 10.1039/ 9781849734905.

[21] Ding H, Ye W, Wang Y, Wang X, Li L, Liu D, et al. Process intensification of transesterification for biodiesel production from palm oil: Microwave irradiation on transesterification reaction catalyzed by acidic imidazolium ionic liquids. Energy 2018;144:957-67. https://doi.org/10.1016/j.energy.2017.12.072.

[22] Ullah Z, Bustam MA, Man Z. Biodiesel production from waste cooking oil by acidic ionic liquid as a catalyst. Renew Energy 2015;77:521-6. https://doi.org/10.1016/j. renene.2014.12.040.

[23] Xu W, Ge X, Yan X, Shao R. Optimization of methyl ricinoleate synthesis with ionic liquids as catalysts using the response surface methodology. Chem Eng $\mathrm{J}$ 2015;275:63-70. https://doi.org/10.1016/j.cej.2015.04.035.

[24] Sun Y, Liang L, Ren T, Qiao Q, Liu Q. Synthesis of methyl oleate catalyzed by acidic ionic liquid [Hmim]HSO4. Zhongguo Youzhi 2015;40:68-71.

[25] European Commitee for Standardization. EN 14104: Fat and oil derivatives - Fatty Acid Methyl Esters (FAME) - Determination of acid value; 2003;3:1-14. doi:10. 3403/02805794.

[26] European Committee for Standardization. EN-14103: Fat and oil derivatives - Fatty Acid Methyl Esters (FAME) - Determination of ester and linolenic acid methyl ester contents; 2003:1-11.

[27] Aranda DAG, Santos RTP, Tapanes NCO, Ramos ALD, Antunes OAC. Acid-catalyzed homogeneous esterification reaction for biodiesel production from palm fatty acids. Catal Lett 2008;122:20-5. https://doi.org/10.1007/s10562-007-9318-z.

[28] Fauzi AHM, Amin NAS, Mat R. Esterification of oleic acid to biodiesel using magnetic ionic liquid: Multi-objective optimization and kinetic study. Appl Energy 2014;114:809-18. https://doi.org/10.1016/j.apenergy.2013.10.011.

[29] Kostić MD, Veličković AV, Joković NM, Stamenković OS, Veljković VB. Optimization and kinetic modeling of esterification of the oil obtained from waste plum stones as a pretreatment step in biodiesel production. Waste Manag 2016;48:619-29. https://doi.org/10.1016/j.wasman.2015.11.052.

[30] Jansri S, Ratanawilai SB, Allen ML, Prateepchaikul G. Kinetics of methyl ester production from mixed crude palm oil by using acid-alkali catalyst. Fuel Process Technol 2011;92:1543-8. https://doi.org/10.1016/j.fuproc.2011.03.017. 